\title{
ESPAÇOS E TEMPOS DE LEITORES E DE LEITURAS: A ESCOLA DO CAMPO EM CONTEXTO
}

\author{
Cella Beatriz Piatti \\ Universidade Federal de Mato Grosso do Sul (UFMS), Campo \\ Grande, Mato Grosso do Sul, Brasil
}

\begin{abstract}
Resumo: Ao trazer para o debate a formação de professores para a escola do campo, evidenciam-se diferentes temáticas, uma delas, a leitura. Para esse espaço, considera-se que, para além de apresentar métodos e técnicas de ensino, é preciso formar profissionais que reconheçam o seu papel político e social frente as demandas do campo. Nesse sentido, a leitura ocupa espaço importante na possibilidade de reconhecer-se como agente de transformação nesse território de busca incessante por direito à educação, melhores condições de vida, de saúde e de trabalho. Para tanto, neste estudo, apresenta-se como objetivo conhecer o espaço da leitura na escola, categoria que surgiu após a coleta de narrativas de 20 participantes, estudantes de uma licenciatura em Educação do Campo. Conclui-se que a leitura acontece em diferentes lugares, mas, às vezes, a escola é o espaço que dá início a esse processo, e o professor é o primeiro a conduzi-lo, mas, nem sempre, a escola cumpre o papel de formar leitores.
\end{abstract}

Palavras-chave: Leitura. Formação. Professores. Escola.

1. INTRODUÇÃO

Ao trazer à tona debates referentes à escola do campo, diferentes questões surgem, algumas em âmbito geral, outras, em relação à singularidade desse espaço. Considera-se que, para uma educação do campo se efetivar na 
escola do campo, faz-se necessário reconhecer o contexto dessa educação, pois é necessário considerar o modus operandi de uma população que vive e trabalha no campo.

Qualquer tema em debate é desafiador, qualquer proposta nos instiga, nos inquieta, uma vez que a educação do campo traz, em seu processo histórico, a história da luta pela terra, a resistência, a persistência, o silenciamento das políticas públicas para o debate dessa educação, durante décadas.

Portanto, discutir temáticas que emergem da educação do campo nos permite pensar nessa população, em sua cultura, em sua identidade. Desse modo, é preciso romper com uma visão de educação unilateral, pois entende-se que

[...] Educação é um processo intencional (planejado e organizado objetivamente, de preferência por coletivos, em uma direção determinada) de busca de desenvolvimento omnilateral do ser humano (CALDART, 2011, p. 65-66).

A autora segue afirmando que a palavra omnilateral indica a busca de um processo de formação humana ou de humanização integral, entendido como totalidade (CALDART, 2011, p. 65-66). Assim, entende-se que não é "a soma da atuação em diferentes dimensões, mas sim a articulação que visa coerência na atuação do ser humano no mundo" (CALDART, 2011, p. 65-66).

Em se tratando de formação humana, busca-se compreender o processo e a emancipação. Nesse sentido, de acordo com Arroyo (2009):

Quando situamos a escola no horizonte dos direitos, temos que lembrar que os direitos representam sujeitos, sujeitos de direitos [...] Sujeitos de história, de lutas, como sujeitos de intervenção, como alguém que constrói, que está participando de um projeto social (ARROYO, 2009, p. 74).

Depreende-se que as questões que emergem dessa educação precisam e devem estar articuladas com as problemáticas que visam pensar o campo em toda a sua plenitude. Nesse sentido, o campo deve ser pensado a partir de sua realidade, pois o desafio está em romper com a visão dicotômica entre urbano e rural, que produz uma ideia que o urbano é mais adiantando e desenvolvido, portanto, o campo é atrasado.

Assim, cabe indagar:

Quais são as bases da opção brasileira por um novo projeto de desenvolvimento nacional, e qual o lugar da educação na construção desse projeto? Quais são as bases da opção brasileira por um novo projeto de desenvolvimento do campo? Que políticas públicas são necessárias para a 
implementação das escolas do campo? Que concepções e que princípios pedagógicos constituem a opção brasileira no campo da educação e permitem a construção da identidade de uma escola do campo? (FERNANDES; CERIOLI; CALDART, 2009, p.44).

Pensar a identidade do campo requer pensar inúmeras questões que possam avançar na organização pedagógica das escolas do campo, uma delas, a formação docente. Com base nessa questão, interroga-se: quem são os professores que atuam nas escolas do campo? O que sabem em relação ao campo? Que propostas pedagógicas apontam para a escola do campo? O que carregam em suas trajetórias para a escola do campo?

São muitas as questões, mas, nos limites deste texto, discute-se a leitura. Que espaço tem a leitura na formação de professores quando situamos a escola do campo e as suas singularidades? O que pensam os professores sobre os processos de leitura? O que viveram no contexto da leitura em sua escolaridade? O que os processos de leitura refletem em sua prática pedagógica? Mas, principalmente, responder à questão: qual o espaço da leitura na escola?

Questão que emerge de categorias criadas após ouvir os participantes do eixo de pesquisa "Sentidos e significados necessários e possíveis para a constituição do professor leitor para além da formação inicial, na licenciatura de Educação do Campo", que está inserido no projeto "Políticas educacionais e formação: produção, projetos e ações de educação e psicologia", aprovado pelo Conselho Nacional de Desenvolvimento Cientifico e Tecnológico (CNPq) em dezembro de 2015, com apoio e financiamento desse órgão.

\section{A EDUCAÇÃO DO CAMPO E A ESCOLA DO CAMPO: UM DEBATE NECESSÁRIO PARA} A FORMAÇÃO DOCENTE

A relação entre formação docente e leitura é alvo de inúmeras indagações quando se discute educação em âmbito geral, bem como a escola do campo e a formação de professores para essa escola. Frente a essa questão, indaga-se: que profissionais são necessários para esse contexto? Outras indagações são necessárias para a compreensão do sentido e do significado de formação: o que é formação? O que é formar para atuar na escola do campo?

Considera-se que, ao situar o processo de formação de professores, cabe lembrar que essa trajetória em nossa história educacional, durante décadas, ancorou-se em conceitos formativos com configurações tecnicistas, mecanicistas, pragmáticas, com enorme distanciamento entre teoria e prática. 
Configurações que interferem na compreensão de formação, principalmente, para esse lócus em discussão, pois, para além de pensar a formação específica, é preciso levar em conta o campo e suas questões políticas e sociais, em relação aos sujeitos de direito para essa escola.

Considera-se que a preocupação referente à formação de professores esbarra nos "velhos" entendimentos e nas promessas de "metodologias inovadoras" que ressoam em diferentes discursos que anunciam uma nova formação e, portanto, uma ideia de melhoria da prática docente.

Todavia, cabe ressaltar que não se discute aqui um modelo de formação, mas possibilidades de uma formação que reconheça o espaço do campo como "um lugar de vida, onde as pessoas podem morar, trabalhar, estudar com dignidade de quem tem o seu lugar, a sua identidade cultural" (FERNANDES, 2009, p. 137).

Situar a educação do campo e a escola do campo em relação à formação docente significa reconhecer que "o campo precisa ser compreendido como um modo de vida sociocultural no sentido de que sejam afirmadas as suas identidades, bem como suas lutas e organizações" (PIRES, 2012, p. 43).

Frente a essa questão, Pires (2012) aponta que, nas escolas do campo, é necessária a construção de uma proposta pedagógica diferenciada. Afirma que

A proposta pedagógica construída pela e com a Escola do Campo deve-se pautar em uma educação que respeite o modo de vida dos povos do campo, sua dinâmica social e acolha seus saberes e experiências (PIRES, 2012, p.117).

De acordo com Arroyo (2007), a organização de uma escola do campo requer uma formação de professores a partir da dinâmica social, política e cultural existente no campo, na perspectiva de reconhecer as lutas pelos direitos de seus povos, pelo direito à terra, a melhores condições de vida, de educação e de uma escola que seja realmente do campo.

Segundo Arroyo,

A história nos mostra que não temos uma tradição nem na formulação de políticas públicas, nem no pensamento e na prática de formação de profissionais da educação que focalize a educação do campo e a formação de educadores do campo como preocupação legítima. Por quê? (ARROYO, 2007, p.157).

O autor segue afirmando que não há uma preocupação com a formação docente, pois há uma inspiração urbana que concebe que, para o campo, basta uma adaptação e, por isso, nos deparamos com "profissionais 
urbanos levando seus serviços ao campo, sobretudo nos anos iniciais, sem vínculos culturais com o campo, sem permanência e residência junto aos povos do campo" (ARROYO, 2007, p. 159).

A despeito disso, podemos afirmar que a formação de professores para as escolas do campo constitui-se em um grande desafio. É preciso pensar práticas pedagógicas e um currículo que supere a visão urbanocêntrica que reduz o campo, como diz Arroyo (2007, p.159), "a uma extensão, um quintal da cidade".

Reitera-se que, "situada a formação neste patamar, são interrogadas as políticas generalistas, é questionado o protótipo de profissional único para qualquer coletivo e são questionadas as normas e diretrizes generalistas que apenas aconselham 'adaptem-se' à especificidade da escola rural" (ARROYO, 2007, p. 165).

Ao pautar a formação de professores para as escolas do campo, cabe ressaltar a importância dos movimentos sociais nessa caminhada da educação do campo e da concretização dessa escola do campo. Essa educação não tem origem na disposição política do Estado, mas dos movimentos sociais ávidos por uma educação que se articule à luta pelo direito à terra, à cultura, à identidade e a melhores condições de vida e de saúde para as comunidades do campo.

Nessa perspectiva, ao refletir sobre a formação docente para atuar na escola do campo, surgem algumas inquietações:

tem sentido pensar em políticas de formação de educadoras e educadores do campo? Seria esta questão uma preocupação legítima para os responsáveis pela formulação de políticas públicas? Seria uma dimensão a merecer a atenção do pensamento sobre formação de educadores? Mais em concreto, seria uma preocupação necessária para o repensar dos currículos dos cursos de pedagogia e licenciatura? (ARROYO, 2007, p. 158).

Nessa caminhada, também cabe lembrar o que pedem os movimentos sociais:

Não pedem um trato diferenciado para a formação de educadores(as) do campo. Reivindicam que não se esqueçam de que a educação do campo existe, e a formação de profissionais específicos que garantam o direito à educação básica de milhões de crianças e adolescentes, de jovens e adultos que vivem no campo tem de ser equacionada (ARROYO, 2007, p. 167).

Equacionada em diferentes situações e uma delas, na formação docente, que precisa reconhecer o campo, as transformações da escola como o currículo que "precisa incorporar o movimento da realidade 
e processá-lo como conteúdos formativos[...]". Uma escola do campo precisa de um currículo que contemple necessariamente a relação com o trabalho na terra (FERNANDES; CERIOLI; CALDART, 2009, p. 57). Para tanto, essa transformação perpassa a formação do professor, pois é preciso compreender o seu papel perante essa escola e suas singularidades, reveladas no Projeto Político Pedagógico em uma construção coletiva, portanto, no currículo e nas práticas pedagógicas.

Frente a essa questão, é necessário relembrar a importância da efetividade dos professores e gestores nas escolas do campo.

Um corpo de docentes e gestores que chega cada dia da cidade à escola rural, sem conhecer os significados dessa tensa realidade na conformação das crianças, dos adolescentes, jovens ou adultos do campo não terá condições de ser educador, educadora, docente, gestor (ARROYO, 2007, p. 171).

O autor ainda afirma que [...] "a maioria das educadoras e educadores vai, cada dia, da cidade à escola rural e de lá volta a seu lugar, a cidade, a sua cultura urbana. Consequentemente, nem tem suas raízes na cultura do campo, nem cria raízes" (ARROYO, 2007, p. 169).

Nesse sentido, a formação de professores deve seguir um caminho que compreenda que

A educação precisa ser compreendida como prática social; tratar o conhecimento de forma inter-relacionada; e ser incentivada à construção de novas possibilidades de vida e permanência no campo como espaço de lutas coletivas de seus sujeitos por melhores condições de vida, de trabalho e de educação (PIRES, 2012, p. 118).

São muitas as questões que revelam a necessidade de pensar o campo, a educação do campo e a escola do campo. Para Molina, "uma escola para ser considerada do campo e para o seu funcionamento é necessário o reconhecimento e a valorização da identidade de seus sujeitos" (MOLINA, 2009, p. 32).

De acordo com Caldart (2009), em se tratando de escola do campo, a escola é mais do que escola, é "lugar de formação humana, significa que ela não é apenas lugar de conhecimentos formais e de natureza intelectual" (CALDART, 2009, p.121), Portanto, é espaço de contradição, de luta e de tensões históricas que revelam a necessidade de articular a escola "às lutas pela reforma agrária, por trabalho, pela defesa da agricultura camponesa, por educação do campo e por outro projeto de escola articulado a outro projeto de campo" (ARROYO, 2012, p. 90). 
Depreende-se que, para formar professores para atuar na escola do campo, não basta conduzi-los a aprender o que ensinar e como ensinar, mas, sobretudo, a quem ensinar, na perspectiva de concretizar uma educação que atenda às necessidades de quem vive a luta pela terra e encontra na escola um espaço que também faz parte da luta.

Os movimentos sociais, em suas manifestações, solicitam que, na formação de professores, tenham lugar questões como:

o conhecimento do campo, as questões relativas ao equacionamento da terra ao longo de nossa história, as tensões no campo entre o latifúndio, a monocultura, o agronegócio e a agricultura familiar; conhecer os problemas da reforma agrária, a expulsão da terra, os movimentos de luta pela terra e pela agricultura camponesa, pelos territórios dos quilombos e dos povos indígenas (ARROYO, 2007, p.167).

É nesse movimento de reconhecimento desse território tenso que tantas questões emergem e que devem ser pensadas na organização da formação docente. Muitas outras questões surgem: formar para onde? Formar em que sentido? Considera-se que a formação deve possibilitar que o professor da escola do campo compreenda que um dos impactos e desafios das lutas da educação do campo

é o reconhecimento da diversidade de trabalhadores do campo brasileiro no momento de elaborar políticas educacionais. Afinal, discutir identidades e culturas tão específicas como a dos indígenas, povos das florestas, ribeirinhos, caiçaras, ilhéus, quilombolas, faxinalenses, assentados, acampados, mulheres camponesas, entre outras, exige esforço pedagógico e político. Corre-se o risco de mascarar as diferenças e diversidades em nome da igualdade (SOUZA, 2012, p.760).

Questão importante a ser equacionada quando se trata de elaborar o Projeto Político Pedagógico das escolas, as atividades educativas, pois o sentido da diversidade não é, nem poderá ser, o sentido da igualdade, ao contrário, deve ser a perspectiva da desigualdade em que se encontram esses sujeitos e, portanto, seus direitos devem fazer parte da luta por uma educação de qualidade e de direitos para os filhos desses trabalhadores.

Frente a essa discussão, o que deve ser trazido à baila são questões necessárias ao debate, resgatando a necessidade de consolidar uma formação para professores atuarem no campo, cientes de seu compromisso com o contexto campesino e suas especificidades.

Considera-se que há muitas questões que precisam ser discutidas e debatidas, estudadas e pesquisadas referentes à educação do campo e à 
escola do campo. Uma delas é a formação de professores, tendo em vista que essa formação deve levar em conta a história dos sujeitos do campo. Depreende-se que, nesse campo de tensões, muitas temáticas de pesquisa e estudo são necessárias, mas, neste texto, a leitura na formação docente é pauta de discussão e, assim, um questionamento se faz necessário: qual a importância da leitura na formação de professores?

\section{A LeITURA NA FORMAÇÃO DOCENTE: UMA DISCUSSÃO NECESSÁRIA}

Compreender o lugar da leitura na formação docente traz inúmeras questões, uma delas a seguinte:"sabemos bem pouco sobre o que os alunos precisam, mas bem pouco ou nada sobre as necessidades dos professores para assumir o desafio imposto por 'nossas inovações' sobre a aprendizagem da leitura" (MIGUEL; PÉREZ; PARDO, 2012, p. 17). Indaga-se também: que“lógica seguimos quando propomos aos professores que adquiram novos recursos [...] sem entender a magnitude e o custo que implica a sua aquisição"? (MIGUEL; PÉREZ; PARDO, 2012, p. 17).

Nesse sentido, Rangel nos alerta: "como a escola colabora para a formação da história de leitura do aluno? Que experiências de leitura são vivenciadas na escola?" (RANGEL, 2012, p. 46).

A despeito da compreensão da escola como um dos espaços propícios à formação de leitores, é importante reconhecer o grande desafio imposto aos professores ao enfrentarem a tarefa de formar leitores e quase sempre de se sentirem na posição de leitores. E, ainda, de responder a esse desafio, diante da ideia de pensarmos como ocorrem os processos de leitura em sala de aula, no seio da família e em outros espaços onde a leitura acontece.

Ao reconhecer a escola como espaço social e a educação como processo social, importante se faz lembrar que, de acordo com Vygotski (1991), não há processos de maturação ou inclinações inatas no desenvolvimento humano, mas o que se coloca em pauta são os mecanismos da maturação que estão fora e não dentro do organismo, o que significa a força do social no desenvolvimento do pensamento humano.

A despeito dessa questão, considera-se que a escola pode ser um dos primeiros espaços onde se tem o contato com a leitura e que o professor pode ser um mediador importante na constituição de leitores. Ressalta-se que, nesse sentido, compreender os processos de leitura dos sujeitos em formação pode trazer importantes elementos para encontrar o lugar da leitura na formação docente.

Conforme nos aponta Soares, 
Aqueles que formam leitores [...] desempenham um papel político que poderá estar ou não comprometido com a transformação social, conforme estejam ou não conscientes da força de reprodução e, ao mesmo tempo, do espaço de contradição presentes nas condições sociais da leitura, e tenham ou não assumido a luta contra aquela (força de reprodução) e a ocupação deste (espaço de contradição) como possibilidade de conscientização e questionamento da realidade em que o leitor se insere (SOARES, 2005, p. 28).

Frente a essa afirmativa, entende-se que ler é prática social. Para Soares (2005), "[...] instrumento de reprodução, mas também espaço de contradição, a leitura é, fundamentalmente, processo político" (SOARES, 2005, p. 2). E, como processo político, contribui para o avanço das ideias de cada indivíduo, na compreensão do mundo a sua volta e da sua posição como sujeito da transformação social.

Depreende-se que a leitura é uma interação do homem com o mundo. Essa interação acontece no movimento da história que, de acordo com Leontiev (2004), só é possível com a transmissão, às novas gerações, das aquisições da cultura humana, por meio da educação. De acordo com Vigotski, "[...] em todas as épocas, independentemente de sua denominação e qualquer que fora a sua ideologia: toda educação tem sido sempre uma função do regime social. Toda educação tem sido sempre essencialmente social" (VIGOTSKI, 1991, p. 159).

Ao considerar a educação como aspecto social, a leitura tem importância como prática política e social. Portanto, por meio dela, o homem entra em contato com um mundo já construído e, dessa forma, compreende o que já existe, mas compreende que é necessário a sua atuação ativa para transformá-lo.

Pensar a formação docente incita-nos a refletir que não lidamos com um produto acabado, neutro, mas em processo constante e dinâmico de desenvolvimento. Qualquer que seja o tema abordado para pensar a formação de professores, é preciso situar o lugar de cada sujeito. Esse lugar apresenta diferentes possibilidades de conhecê-lo e reconhecê-lo frente ao objeto de estudo, aqui a leitura, como um dos elementos de formação importantes e necessários para a docência.

Nesse caminho, cabe indagar: o que é a leitura? De qual leitura estamos falando? O que é ler na escola ou fora dela? Quem é o professor? O que significa para o professor o processo de ler? Para esses questionamentos há, com certeza, inúmeras respostas e diferentes concepções sobre o ato de ler. 
Ler é compreender-se inserido no processo histórico construído pela humanidade e, portanto, nesse processo, encontram-se aspectos importantes da vida humana (sociais, culturais, políticos, cognitivos).

Ler é processo político, pois, ao se confrontar com as informações advindas da leitura, o homem se constitui ou não leitor, pois, dependendo desse processo, há também as possibilidades de torna-se alienado. Nesse sentido, vamos ao encontro das indagações de Rangel: como a escola colabora para a formação da história de leitura do aluno? Que experiências de leitura são vivenciadas na escola? (RANGEL, 2012, p.46). Responder a essas questões nos leva a considerar os desafios impostos aos professores, a sua posição de destaque diante dos processos de leitura que acontecem na escola.

Entende-se que ler nesse sentido não é apenas a possibilidade de decifrar um código, memorizar ou interpretar o que dizem os autores. É, acima de tudo, ler o mundo e o que ele nos apresenta, é ter autonomia para pensar sobre esse mundo na perspectiva de transformá-lo e emancipar-se como sujeito social que vive culturalmente o processo social.

A discussão sobre a leitura, principalmente sobre a leitura numa sociedade que pretende democratizar-se, começa dizendo que os profissionais mais diretamente responsáveis pela iniciação na leitura devem ser bons leitores. Um professor precisa gostar de ler, precisa ler muito, precisa envolver-se com o que lê (LAJOLO, 2000, p.108).

Assim, considera-se que a leitura não é prática neutra, mas carregada de ideologias, de ideias e de ideais. Logo, ao ler, o homem entra em contato com diferentes possibilidades de posicionamentos e tem condições de refletir, confrontar e refutar ideias já postas pela sociedade, por isso, a leitura pode contribuir para a emancipação do homem na sociedade.

\section{NARRAM-SE MOMENTOS DE LEITURA NA ESCOLA}

Este estudo integrou as atividades realizadas no eixo "Sentidos e significados necessários e possíveis para a constituição do professor leitor para além da formação inicial, na licenciatura de Educação do Campo", que está inserido no projeto "Políticas educacionais e formação: produção, projetos e ações de educação e psicologia", aprovado pelo Conselho Nacional de Desenvolvimento Cientifico e Tecnológico (CNPq) em dezembro de 2015, com apoio e financiamento desse órgão. A pesquisa tem como objetivo investigar as políticas educacionais de formação inicial e/ou continuada, por meio da análise da produção, de programas, de projetos e de ações em Educação e Psicologia em Mato Grosso do Sul, evidenciando articulações com o contexto social, cultural e educacional do Estado. 
O objetivo desse eixo consiste em ouvir os professores que são estudantes de uma licenciatura em Educação do Campo. Entre diferentes temas que nos incitam a investigar a formação docente, a leitura é um deles, pois, independente da área de atuação do professor, ela é alvo frequente das atividades e da própria aprendizagem do professor.

Nesse eixo, a pesquisa foi organizada em seu campo empírico, no primeiro momento, com o levantamento bibliográfico por meio do método de investigação estado do conhecimento, para conhecer o que já foi produzido em relação à temática. No segundo momento, foi realizada a pesquisa de campo, que contou com atividades de intervenção com oficinas de leitura, rodas de conversa e com o recolhimento de narrativas que visaram dar voz aos atores sociais que estão na escola e vivenciam os processos de leitura em seu dia a dia, etapa que apresentaremos neste estudo.

Participaram 20 professores, estudantes dessa licenciatura em Educação do Campo da Universidade Federal de Mato Grosso do Sul, licenciados em diferentes áreas de conhecimento e que buscam na licenciatura em Educação do Campo a formação específica para atuar na escola do campo.

Como critérios, foram selecionados sujeitos que estudaram em escolas do campo, durante os primeiros anos do ensino fundamental, e que já atuam como professores em escolas do campo em diferentes áreas de conhecimento (Língua Portuguesa, Matemática, História, Geografia e Artes).

Para este estudo, apontam-se alguns resultados das análises das narrativas, dos participantes, privilegiando as categorias que foram criadas e organizadas. De posse das narrativas dos 20 participantes da pesquisa, destacaram-se 11 categorias que nos conduziram a compreender diferentes aspectos e características do ato de ler na escola. São elas: 1. Primeiro contato com os livros; 2. Como o professor se constitui leitor; 3 . Influência da escola na formação de leitores; 3 . Leituras apresentadas na escola; 4. Motivação recebida para leitura; 5 . Espaço da leitura na escola; 6 . Leitura: prazer ou obrigação?; 7. Leituras na infância; 8. Primeiras leituras na escola; 9. Leitura como processo cultural e social; 10 . Práticas de leitura na escola e fora dela; 11. Relação pessoal e profissional com os processos de leitura.

Para esta discussão, traz-se a categoria "Espaço da leitura na escola". Nos discursos dos sujeitos, compreende-se que a escola pode ser um dos primeiros espaços de leitura, porém, a leitura acontece em inúmeros outros espaços. Parece-nos, contudo, que a escola fica em posição de evidência quando o sujeito relata a sua história de leitura. 
Com base nas narrativas, considera-se que a escola pode ser um dos primeiros espaços de contato com a leitura, o professor pode ser o condutor desse processo e, logo, é preciso considerar quais são as leituras e como elas são apresentadas às crianças e aos jovens.

Portanto, cabe indagar: quais são as leituras apresentadas na escola? O que elas propiciam aos leitores em formação? O que essas leituras representam nas trajetórias de futuros formadores de leitores? Questões que podem ser respondidas nesse processo de pesquisa ainda em andamento de investigações e análises.

Nos limites deste texto, embora em uma análise, mesmo que preliminar, das questões em discussão, apresentam-se como ilustração narrativas de alguns sujeitos participantes da pesquisa em tela.

Cabe ressaltar que nossa intenção não é quantitativa, mas sim de valor qualitativo, de acordo com as narrativas que evidenciam trajetórias vivenciadas pelos acadêmicos enquanto ainda estavam em processo de escolarização na educação básica.

Assim, o que nos interessa são trechos que apontem o trabalho com a leitura no processo de formação deste sujeito que ingressou na Licenciatura em Educação do Campo e que já atua como professor em áreas específicas, lidando, portanto, em seu dia a dia com a leitura.

Em relatos, um acadêmico afirma:

Aprendi a ler na escola, morava em acampamentos. Hoje, em um lugar e, amanhã, em outro, uma escola e outra, uma professora e depois outra. Era difícil, não tínhamos brinquedos, livro, então, era artigo de rico. Na escola não tinha livros, eram apenas os cadernos e a professora apresentava uns livrinhos de história, já bem "surrados", era o que tinha. Na escola, não via prazer em ler, apenas a obrigação devido às tarefas. Sentia vontade de ler, mas era tudo muito precário, acho que por isso hoje não tenho tanto prazer em ler.

Esse relato traz à tona indagações importantes: como reconhecerse frente às questões emergentes do campo sem que a leitura seja parte dessa caminhada? Como construir a identidade como professor do campo, se a leitura não é prioridade nas atividades realizadas? Se a leitura conduz a reflexões sobre o que está a nossa volta, é necessário afirmar que aqueles que formam leitores "[...] desempenham um papel político que poderá estar ou não comprometido com a transformação social, conforme estejam ou não conscientes da força de reprodução e, ao mesmo tempo, do espaço de contradição presentes nas condições sociais da leitura" (SOARES, 2005, p.28).

Ao narrar sua história de leitura, a acadêmica diz: 
Gosto de ler, aprendi a ler mesmo na escola, na cartilha, acho que como todos da minha época. Também acho que ler é para vida toda, por isso não vejo na escola a única responsável por essa leitura. Livro no Brasil é muito caro, com o nosso salário de professor, sem livros bons na biblioteca da escola, é difícil ler, além das necessidades da sua disciplina.

Quando o professor justifica a sua falta de leitura, afirmando o alto custo do livro, nos reportamos a Lajolo, ao apontar que

Numa sociedade como a nossa, em que a divisão de bens, de rendas e de lucros é tão desigual, não se estranha que desigualdade similar presida também à distribuição de bens culturais já que a participação em boa parte destes últimos é mediada pela leitura, habilidade que não está ao alcance de todos, nem mesmo de todos aqueles que foram à escola (LAJOLO, 2000, p.106).

Nesse sentido, há sempre uma questão em evidência, segundo a qual o professor deve ser bom leitor, deve sentir-se nessa posição privilegiada de leitor e, mais ainda, é o responsável, no interior da escola, pela formação de leitores. Responsabilidade hercúlea, para quem também sentiu dificuldades em seu processo de tornar-se leitor.

Em outros discursos, os acadêmicos revelam:

Antes de ir para a escola, o meu contato com livros foi em casa com a cartilha do meu irmão mais velho. Ele fazia as tarefas e eu folheava a cartilha e ele me ensinava algumas palavras. Quando fui para a escola já tinha noção de leitura, mas aprendi mesmo na escola. Só que não tinha acervos na escola, nossas leituras eram mais na cartilha e depois no livro didático.

Meu primeiro contato com a leitura foi em casa e na igreja. Tinha contato com a bíblia na minha casa, meus pais liam a bíblia em voz alta junto com os filhos e para mim, esse foi o meu primeiro contato com a leitura e interesse. Hoje, é meu livro preferido. Depois na escola li outras coisas, gibis, a cartilha, jornais, e aqueles famosos livros clássicos que éramos obrigados a ler e a fazer atividades, mas hoje, como professora, entendo que não tem outro caminho, se não for obrigado, as crianças e os jovens não querem ler.

Nesses relatos, percebe-se que "a leitura provoca reações diversas nos indivíduos, sejam eles outros ou o mesmo leitor em ocasiões distintas" (ZILBERMAN, 2002, p.28). Também revelam que "raras vezes a escola, seu aparato, como salas de aula, seus instrumentos, como o livro didático e sua metodologia, como a execução do dever de casa, provocam lembranças aprazíveis de leitura" (ZILBERMAN, 2002, p.27). 
Ainda em outros discursos, surgem questões mais reveladoras sobre a escola como espaço de leitura.

Contato com livros era pouco, éramos muito pobres, mas meu pai dizia que os filhos deviam ser mais que ele e, por isso, a escola era importante. Foi nesse contexto que aprendi a ler. Cheguei com muito desejo de ler e aprendi, em livros didáticos. Não era prazeroso, tinha que ler aquilo que a professora exigia, a parte que ela solicitava. Ler mesmo com vontade, com imaginação, como numa viagem, não consegui. Depois crescemos e temos que trabalhar e a leitura vai ficando em segundo plano. Claro, leio para me informar melhor sobre diferentes assuntos, pois os alunos precisam dessas informações, mas fica nisso...

Ler é bom demais, passa o tempo, diverte, mas a correria do dia a dia, nem permite muito essa leitura, mas eu tento sempre que posso. Na escola a leitura deveria ser mais atraente, mas também, hoje, como professora, entendo que o tempo é nosso inimigo, temos que dar conta de muitas coisas na escola, então, ler mesmo, não dá muito tempo. Mas tento fazer projetos de leitura, assim, fico mais tranquila, com a sensação do dever cumprido e de incentivo para a leitura.

Cada um tem a sua trajetória de leitura, algumas com resultados mais promissores, outras nem tanto. Mas a escola como um dos lugares onde as crianças e os jovens se deparam com a leitura às vezes apresenta atividades áridas e sem cunho motivador. Nesse sentido, afirma Zilberman:

As atividades pedagógicas provocam tédio, quando são vivenciadas como aprisionamento, controle ou obrigação. A leitura parece ficar do lado de fora, porque os professores não a incorporam ao universo do ensino (ZILBERMAN, 2002, p.27).

Formar leitores é um compromisso social que não se esgota na formação inicial do sujeito (Educação Infantil, Ensino Fundamental e Médio), bem como não é privilégio da disciplina de Língua Portuguesa, mas de todas as disciplinas e de todos os professores em qualquer área do conhecimento e em todos os segmentos da escolarização.

É fato que, ao adentrar nas licenciaturas, muitos estudantes ainda sentem dificuldades referentes à leitura, o que reforça a necessidade de investimento nesse tema para a formação de futuros professores.

Contudo, cabe ressaltar que a leitura não é diferente, quando se trata de Educação do Campo, mas ela é instrumento social e, portanto, confere aos leitores oportunidades de ver o mundo com criticidade para 
transformá-lo. Pode ser instrumento de alienação, quando não entendida nesse processo social.

Ler é uma prática política e social e o espaço escolar é também um lugar de lutas, de contradições e de resistência, portanto, um espaço necessário e importante para que a leitura seja garantida como possibilidade de reflexão e atuação de alunos e professores na escola do campo, reconhecendo-a como um direito, articulado ao direito à terra, ao trabalho e à educação.

Dessa forma considera-se que o professor deve ser leitor, deve ler com frequência e identificar-se como leitor e se reconhecer nessa condição ou corre-se o risco de fazer a escola palco de aversão ao processo de leitura. Desse modo, outras questões também são necessárias para o aprofundamento desse debate, como reconhecer as condições de trabalho dos professores, a precariedade dos acervos nas bibliotecas das escolas, ou a ausência da biblioteca na escola, os recursos e artefatos de leitura que nem sempre são disponíveis aos professores em sala de aula.

Questões que merecem ser analisadas, uma vez que se atribui aos professores a responsabilidade e a árdua tarefa de formar leitores e, mais, de serem leitores ativos para que essa condição os torne capazes de formar outros leitores.

Posto isso, entende-se que

Em nossa cultura, quanto mais abrangente a concepção de mundo e de vida, mais intensamente se lê, numa espiral quase sem fim, que pode e deve começar na escola, mas não pode e (nem costuma) encerrar-se nela (LAJOLO, 2000, p. 7).

Nesse sentido, entende-se que a leitura pode iniciar na escola, mas deve ultrapassar os seus muros. O leitor precisa encantar-se e, ao mesmo tempo, encontrar no ato de ler as possibilidades de conhecer o mundo. Assim,

Do mundo da leitura a leitura do mundo, o trajeto se cumpre sempre, refazendo-se, inclusive, por um vice-versa que transforma a leitura em prática circular e infinita. Como fonte de prazer e de sabedoria, a leitura não esgota seu poder de sedução nos estreitos círculos da escola (LAJOLO, 2000, p. 7).

A escola pode ser o primeiro espaço para o futuro leitor entrar em contato com a leitura, o professor pode ser o primeiro a intervir nesse longo processo que é o ato de ler e formar leitores. Nesse sentido, cabe indagar: qual é o espaço da leitura na escola?

Espaço que às vezes não contribui em sua organização para a formação de leitores. Aqui, não se trata de ler apenas pelo prazer, mas de 
encontrar na leitura as possibilidades de compreender que, por meio dela, há possibilidades de viver com intensidade as questões sociais que são alvo constante de nossas decisões, de nosso confronto e, mais ainda, de nossa intervenção. A leitura, nesse sentido, pode ser instrumento de transformação ou, se não for vista assim, pode ser de total alienação.

\section{ConsiderAÇÕES FINAIS}

"Pensar pensamentos alheios não implica apenas compreendê-los, mas supostamente conduz a uma alteração naquele que pensa, o leitor" (ZILBERMAN,2002, p. 29).

Embora com apenas alguns trechos ilustrativos, nossa análise revela que há inúmeras respostas e possibilidades de compreender os sujeitos em processos de leitura. Quando nos propomos a investigar professores em formação, são diversas as questões que surgem e que representam as suas ações na formação de futuros leitores no espaço escolar, mas também revelam suas dificuldades de posicionar-se como leitor, frente à imposição posta em sua ação.

A epígrafe acima nos incita a pensar que a leitura é instrumento de luta, por uma formação que possibilite ao professor utilizá-la em prol da melhoria de sua prática em diversas situações, mas, principalmente, no sentido de formar-se leitor e, portanto, contribuir na formação de crianças e jovens leitores.

Por isso, consideramos que a leitura na formação docente não tem especificidade, em qualquer licenciatura, ela deve ser questionada e compreendida. Mas, ao ser pensada na licenciatura em Educação do Campo, junto aos professores das escolas do campo, revela importância inconteste, pois pode ser um dos instrumentos de luta pelos direitos reivindicados pela população do campo.

Entre tantas questões referentes à leitura no interior da escola, temos como aporte as ideias de Lajolo (2000), ao afirmar que é necessário "balizar os projetos que objetivem efetiva democratização e qualificação das práticas - sobretudo escolares - de leitura no Brasil" (LAJOLO, 2000, p.72). A autora segue afirmando que as atividades escolares referentes à leitura na escola são muitas vezes "distribuídas em pacotes endereçados e anônimos e despreparados professores passam a representar a varinha mágica que transformará crianças mal alfabetizadas, sem livros disponíveis, em bons leitores" (LAJOLO, 2000, p.72). 
Diante dessa afirmativa, muitas outras questões surgem: os professores que já atuam nas escolas têm acesso a bons materiais de leitura? Os professores de diferentes áreas nas licenciaturas se preocupam com a formação de leitores?

Compreende-se que, ao serem inseridos nesse mundo de artefatos literários, garante-se o direito à leitura, pois há um confronto de ideias, de ideais, mas, sobretudo, é preciso compreender que a leitura oferece a oportunidade de entender o que está a nossa volta, de contrapor, de confrontar e de transformar e, portanto, de promover a inserção do homem no mundo, no qual ele desempenha papel importante, pois ler é prática política e social.

Nessa perspectiva, o espaço escolar é também um lugar de lutas, de contradições e de resistência, portanto, espaço necessário e importante para que a leitura seja garantida como possibilidade de reflexão e atuação de alunos e professores na escola do campo, reconhecendo-a como um direito, articulado ao direito à terra, ao trabalho e à educação.

As dificuldades encontradas pelos professores revelam que eles esbarram em situações adversas que interferem em sua aproximação com a leitura. Assim, as práticas pedagógicas ficam comprometidas e a leitura no espaço escolar, muitas vezes, torna-se esvaziada de sentido.

Contudo, conclui-se que a leitura acontece em diferentes lugares, mas, às vezes, a escola é o espaço que dá início a esse processo, e o professor é o primeiro a conduzi-lo, Mas, nem sempre, a escola cumpre o papel de formar leitores.

Artigo recebido em: 22/11/2017 Aprovado para publicação em: 18/03/2018

\section{SPACES AND TIMES OF READERS AND READINGS: THE SCHOOL OF THE FIELD IN CONTEXT}

ABSTRACT: Discussing about teacher's formation for field school, it is evident different themes, one of them, the reading. For this space, it is considered that, in addition to presenting teaching methods and techniques, it is necessary to train professionals who recognize their political and social role in the demands of the field. In this sense, reading occupies an important place in the possibility of recognizing itself as an agent of transformation in this territory of incessant search for the right to education, the better conditions of life, health and work. Therefore, in this study, the objective is to know the reading space in the school, a category that arose after the collection of narratives of twenty participants, students of a degree in Field Education. It is 
concluded that reading happens in different places, but sometimes the school is the space that initiates this process, and the teacher is the first to lead it, but not always, the school fulfills the role of forming readers.

KEYWORDS: Reading. Training. Teachers. School.

\section{ESPACIOS Y TIEMPOS DE LECTORES Y DE LECTURAS: LA ESCUELA EN CONTEXTO}

RESUMEN: Al traer a debate la formación de profesores para la escuela del campo, se evidencian distintas temáticas, una de ellas, la lectura. Para ese espacio se considera que, para más allá de presentar métodos y técnicas de enseñanza, es necesario formar profesionales que reconozcan su rol político y social frente a las demandas del campo. En ese sentido, la lectura ocupa espacio importante por la posibilidad de reconocerse como agente de transformación en ese territorio de búsqueda incesante por derecho a la educación, a las mejores condiciones de vida, de salud y de trabajo. Para tanto, en ese estudio, se presenta como objetivo conocer el espacio de la lectura en la escuela, categoría que surgió tras el recogimiento de narrativas de veinte participantes, estudiantes de una licenciatura en Educación del Campo. Se concluye que la lectura se pasa en diferentes lugares, pero a veces, la escuela es el espacio que da inicio a ese proceso y el profesor es el primero a conducirlo, pero no siempre, la escuela cumple el papel de formar lectores.

Palabras-Clave: Lectura. Formación. Profesores. Escuela.

\section{REFERÊNCIAS}

ARROYO, M. G. A Educação Básica e o movimento do social do campo. In: ARROYO, M. G; CALDART, R. S; MOLINA, C. M. (Org.). Por uma educação do campo. Petrópolis, RJ: Vozes, 2009.

. Trabalho e educação nas disputas por projetos de campo. Trabalho e Educação, UFMG, v.21, n.3.set./dez. 2012.

. Políticas de formação de educadores (as) do Campo. Caderno Cedes, Campinas, v. 27, p.157-176, maio/ago. 2007. Disponível em: <https://goo.gl/PMg8a3>. Acesso em: 11 ago. 2017.

CALDART, R. S. (Org.). Caminhos para a transformação da escola: reflexões desde práticas da licenciatura em educação do campo. São Paulo: Expressão Popular, 2011.

. A escola do campo em movimento. In: ARROYO, M. G; CALDART, R. S; MOLINA, C. M. (Org.). Por uma educação do campo. Petrópolis, RJ: Vozes, 2009.

FERNANDES, B. M; CERIOLI, P. R; CALDART, R. S. Primeira Conferência Nacional 'Por uma Educação Básica do Campo': texto preparatório. In: ARROYO, M. G; CALDART, R. S; MOLINA, C. M. (Org.). Por uma educação do campo. Petrópolis, RJ: Vozes, 2009. 
FERNANDES, M. B. Diretrizes de uma caminhada. In: ARROYO, M. G; CALDART, R. S; MOLINA, C. M. (Org.). Por uma educação do campo. Petrópolis, RJ: Vozes, 2009.

LAJOLO, M. P. A formação do leitor no Brasil. São Paulo: Ática, 2000.

LEONTIEV, A. O desenvolvimento do psiquismo. São Paulo: Centauro, 2004.

MIGUEL, E. S; PÉREZ, J. R. G; PARDO, J. R. Leitura na sala de aula: como ajudar os professores a formar bons leitores. Porto Alegre: Penso, 2012.

MOLINA, C. M. Cultivando princípios, conceitos e práticas. Presença Pedagógica, Belo Horizonte, v.15, n. 88, p. 30-36, jul./ago. 2009.

PIRES, A. M. Educação do campo como direito humano. São Paulo: Cortez, 2012. (Coleção Educação e Direitos Humanos).

RANGEL, N. M. J. Leitura na escola: espaço para gostar de ler. Porto Alegre: Mediação, 2012.

SOARES, M. B. As Condições sociais da leitura. In: ZILBERMAN, R; SILVA, E. T da. (Org.). Leitura: perspectivas interdisciplinares. São Paulo: Ática, 2005.

SOUZA, M. A. Educação do campo, desigualdades sociais e educacionais. Educ. Soc., Campinas, v. 33, n. 120, p. 745-763, jul./set. 2012. Disponível em: http://www.cedes. unicamp.br. Acesso em 20 out. 2017.

VIGOTSKI, L. S. Problemas teóricos y metodológicos de la psicologia. Madri: Visor, 1991. (Obras escolhidas, volume 1),

ZILBERMAN, R. Formação do leitor na história da leitura. In: PEREIRA, V.W (Org.). Aprendizagem da leitura: ciências e literatura no fio da história. Porto Alegre: EDIPUCRS, 2002.

Celia Beatriz Piatti: Graduada em Pedagogia - Licenciatura Plena Faculdade de Filosofia, Ciências e Letras de Ituverava, com especialização em Administração Escolar e Orientação Educacional. Mestre em Educação pela Universidade Católica Dom Bosco (2006) e Doutora em Educação pela Universidade Federal de Mato Grosso do Sul (2013). Atualmente é integrante do Grupo de Estudos e Pesquisa em Psicologia e Educação (GEPPE). Professora da UFMS, lotada na Faculdade de Educação, atuando como docente no curso de Licenciatura em Educação do Campo-LeduCampo e no Mestrado do Programa de Pós-Graduação em Educação da Universidade Federal de Mato Grosso do Sul. Tem experiência na área de educação, atuando em ensino, pesquisa e extensão com os seguintes temas: Educação do Campo; Constituição do sujeito; Formação de professores na perspectiva histórico cultural.

E-mail: celiabpiatti@smail.com 